doi: 10.15503.jecs2021.2.211.223

Journal of Education Culture and Society No. 2_2021

\title{
UNDERSTANDING MENTAL HEALTH HELP- -SEEKING PREFERENCES OF CHINESE YOUNG OVERSEAS STUDENTS, AND THEIR PERCEIVED BARRIERS AND FACILITATORS TO SEEK HELP
}

\author{
FENGJIAO LIU \\ Moray House School of Education and Sport \\ College of Arts, Humanities \& Social Sciences \\ University of Edinburgh Moray House School of Education and Sport \\ Holyrood Road, EH8 8AQ Edinburgh, United Kingdom \\ E-mail address: $499517388 @$ qq.com \\ ORCID: https://orcid.org/0000-0003-4050-8282
}

\begin{abstract}
Aim. The research explores the mental health help-seeking preferences of Chinese young overseas students (CYOS) as well as their perceived barriers and facilitators to seek help.

Methods. Eight Chinese young overseas students who are currently studying in the US were interviewed, and a thematic analysis was undertaken on their responses.

Conclusions. Five barriers and six facilitators were identified. Young overseas students considered perceiving the problems as not serious, negative attitude toward help seeking, being not willing to burden somebody else, lack of understanding of the process of mental health support, and issues of confidentiality and trust as the most important barriers to help seeking. Facilitators include positive attitudes towards help seeking, positive relationship with help providers, perceiving the problem as serious, easy access, confidentiality and trust, and previous habit of seeking help.

Research restrictions. The samples are relatively homogeneous and could not represent all CYOS and thus lacked generalisability. Only interviews were applied for data collection, which has an impact on the credibility and trustworthiness of the research.

Practical application. Strategies for improving help-seeking should focus on improving mental health literacy of these young people, their peers and parents, building positive relationships with help providers, and cultivating good help-seeking habits before they go abroad.
\end{abstract}

Key words: help-seeking preferences, Chinese young overseas students, barriers and facilitators to seek help 


\section{INTRODUCTION}

$M$ ental health is an essential component of health and plays a fundamental role in the development of both individuals and the society as a whole, and has gradually become a priority in public concern. As Ronald C. Kessler, Wai Tat Chiu, Olga Demler, Kathleen R. Merikangas and Ellen E. Walters (2005) point out, mental health of adolescents needs special attention, since half of all lifelong mental health disorders emerge before the age of 14. These individuals face higher risks of mental health problems due to a series of changes, such as being separate from parents, establishing independent identities, making decisions for their education and career, forming intimate relationships, and developing group affiliations with peers (Commonwealth Department of Health and Aged Care, 2000). Furthermore, poor mental health may have an important impact on adolescents' broader health and long-term development and may result in negative health and social outcomes.

Many countries and organisations are working on mental health promotion, prevention and early intervention of mental health problems for adolescents (Commonwealth Department of Health and Aged Care, 2000). Now there are abundant sources for young people to seek help when they are in difficulties and their help-seeking behaviours are fundamental to their wellbeing and mental health. A growing number of studies have been conducted to investigate help-seeking preferences of Chinese overseas students in higher education, but research on Chinese young overseas students (CYOS) is comparatively limited. CYOS refers to the students, aged from 13 to 15 -years-old, who are currently studying abroad. This research will focus on the help-seeking preferences of CYOS as well as their perceived facilitators and barriers to seek help.

\section{LITERATURE REVIEW}

Mental health $(\mathrm{MH})$ is also an essential component of health, since health refers to physical, mental and social wellbeing and not merely the absence of disease or infirmity (World Health Organisation [WHO], 2001).

Young people are facing a heightened risk of mental health problems (Kessler et al., 2005), which generally refer to temporarily experienced ill mental health and common mental complaints as people react to stress in life, such as depression, anxiety, eating disorder, psychosis, substance misuse, and self-harm (Commonwealth Department of Health and Aged Care, 2000). Without effective intervention, these mental health problems might develop into mental disorder, a diagnosable illness which has more severe influence on an individual's cognitive, emotional and social abilities and has longer duration than mental health problems (Commonwealth Department of Health and Aged Care, 2000). 


\section{Young people's help-seeking preferences}

Adolescence and young adulthood have been recognised as critical periods for promoting mental health and wellbeing (WHO, 2002). Debra Rickwood, Frank P. Deane, Coralie J. Wilson and Joseph Ciarrochi (2005) categorise the sources for seeking help according to the level of formality: informal help-seeking sources refer to those from informal social relationships such as parents, other family members and friends; formal help-seeking sources are from professionals who play a recognised role and receive mental health training so as to provide professional help and advice, such as teachers, school counselors, youth workers, and $\mathrm{MH}$ professionals. Both formal and informal help seeking involve social relationships and require interpersonal skills. In addition, people can also seek help from sources without contacting others, such as Internet (Cakar \& Savi, 2014).

Generally, there are four basic help-seeking preferences of young people. First, young people are reluctant to seek professional help. National surveys in Australia, the UK, and the USA estimate that only $25-26 \%$ of children and adolescents access to specialist MH services (Green, McGinnity, Meltzer, Ford, \& Goodman, 2005; Lawrence et al., 2015; Merikangas et al., 2011). Similarly, a large-scale research studied 11,000 Norwegian adolescents (15-16 years old) and found that only $34 \%$ of them had sought help for depression and anxiety symptoms in the last 12-month period (Zachrisson, Rodie, \& Mykletun, 2006).

Second, the majority of young people prefer informal sources, such as family and friends, to formal sources. It was found that most of the Australian adolescent samples sought help from peers and family members for their mental health problems, while professional groups including mental health practitioners, GPs, alternative health practitioners and educational workers were consulted less frequently (Rickwood, 1992). In the UK, only 12-16\% of pupils considered teachers as helpful and below 20\% pupils regarded school-based professionals (school nurses, counselors, and pastoral support) as helpful (Leavey, Rothi, \& Paul, 2011). In Australia, young people of 12-17 years old tend to seek help from informal sources such as friends and family (Lubman et al., 2017).

Third, some young people were found to prefer to seek help from no one rather than from others (Boldero \& Fallon, 1995). In their study, when asked whether they sought help from others for a specific problem, 438 of the total 1013 respondents indicated they had not. The preference for self-reliance was also found in recent studies (Gulliver, Griffiths, \& Christensen, 2010; Rickwood, Deane, \& Wilson, 2007). Researchers also found that between a third and one half of adolescents do not prefer to seek help for $\mathrm{MH}$ problem such as self-harm (Rowe et al., 2014).

Lastly, the type of problem is likely to determine in what sources to seek help. Early studies indicate both adolescents and adults consult different sources for help based on the type of problem (Rickwood, 1992; Wintre \& Crowley, 1993). Young people tend to discuss interpersonal relationship problems with friends, personal problems with parents, and education and career problems with teachers (Boldero \& Fallon, 1995; Offer, Howard, Schonert, \& Ostrov, 1991). 
A recent study also shows that young people consider health professionals as the main source of help for depressive symptoms, followed by friends and parents; and regard friends as the main help-seeking source for alcohol and other drug problems, followed by health professionals and parents (Lubman et al., 2017).

\section{The barriers and facilitators for young people to seek help}

The help-seeking process was formulated as a four-step model: being aware of having $\mathrm{MH}$ problems, expressing symptoms and need for $\mathrm{MH}$ help, finding available sources for seeking help, and being willing to disclose to sources (Rickwood et al., 2005). Based around this model, researchers identified the major help-seeking barriers for young people, including low emotional competence, the negation of help, and negative attitudes towards seeking help from professionals. They also found a few facilitators of help seeking, including emotional competence, positive attitudes, past experience and mental health literacy, social encouragement from others such as parents and gatekeepers (Rickwood et al., 2005).

Amelia Gulliver et al. (2010) find thirteen barrier themes from qualitative analysis and put them in order according to the frequency of being mentioned in the studies, including public, perceived and self-stigmatising attitude to mental illness, confidentiality and trust, having difficulties in recognising the symptoms of a mental illness, concern about the characteristics of the service provider, self-reliance, knowledge about $\mathrm{MH}$ service, fear or stress about help-seeking or the source, lack of accessibility, difficulty or unwillingness to express emotion, unwillingness to burden other people, prefer other help-seeking sources, worry about negative effect on career development, and others not recognising the need for help or not having the skills to cope; quantitative data analysis demonstrates that the top rated barriers are stigma and discomfort discussing mental health problem, self-reliance and no perceived need for help. Other barriers referred in some studies include feeling that professional service is too expensive (Sheffield, Fiorenza, \& Sofronoff, 2004), believing that no person or helping service could help (Dubow, Lovko Jr, \& Kausch, 1990; Sheffield et al., 2004), and being worried that the counselor would tell the problems to others (West, Kayser, Overton, \& Saltmarsh, 1991).

Facilitators were relatively less researched (Rickwood, Mazzer, \& Telford, 2015). In the limited analysis, eight facilitator themes emerged in three studies, including positive prior experiences of seeking help, social support and encouragement from others, confidentiality and trust, positive relationship with service provider, previous education and $\mathrm{MH}$ awareness, perceiving the problem as serious, feeling easy and open to express emotion, and positive attitudes toward seeking help (Gulliver et al., 2010).

\section{CYOS' mental health and help-seeking strategy}

An increasing number of studies have been conducted to investigate mental health problems of Chinese young overseas students (CYOS) and the attributing factors in recent years. However, research on overseas students' 
help-seeking preference mainly focuses on the stage of higher education. Wei Chen Tung (2011) investigated help-seeking behaviours among international students at colleges and universities in the US. Factors influencing university students' preferences for mental health professionals include cultural barriers which were identified to be fear of stigma, language difficulties, low treatment credibility and perceived discrimination; and practical barriers such as lack of knowledge of symptoms and available sources to seek help, concern about time, cost and transportation and available culturally suitable services (Blignault, Ponzio, Rong, \& Eisenbruch, 2008; Ho, Hunt, \& Li, 2008). Facilitators are relatively less researched.

More research should be done to understand the CYOS aged around 14 when they are facing higher risks of mental health problems (Kessler et al., 2005), in order to provide appropriate early intervention and promote their mental health. This research will focus on CYOS aged 13-15 who study in American middle schools, aiming to address two research questions:

- What are the help-seeking preferences of CYOS?

- What are their perceived barriers and facilitators to seek help?

\section{METHOD}

Case study is site for the employment of this research. It is a strategy specifically focusing on obtaining understanding of the dynamics within single settings (Eisenhardt, 1989), and it is ideal when a researcher asks 'how' and 'why' questions about a contemporary set of events over which the researcher is not required control (Gray, 2018).

Convenience sampling and purposive sampling were used in the study. In this study, a head teacher in an English training school located in Beijing and her online students were invited to participate in the research because they were the most convenient persons for the researcher to access. In order to sample participants in a strategic way, purposive sampling was also used to ensure that the sampled were related to the research questions that were posed (Bryman, 2015). Specific criteria for inclusion included: 1) the research participants should be CYOS who are studying in American middle schools, 2) the age range is 13-15 years old. Eight participants (5 males and 3 females) participated in the research and their background information is shown in Table 1.

The participants and their parents were provided with more detailed information about the research and were asked to confirm their participation. When they understood and agreed, they were involved in the study. Ethics approval for this study was granted by the Ethics Committee at Moray House of Education, University of Edinburgh. The research was conducted following the British Psychological Society (BPS) ethical guidelines. Pseudonyms are used to replace participants' real names to ensure confidentiality and anonymity. 
Interview questions

\section{Question 1:}

Could you tell me how you understand mental health?

Answers:

(B) I think mental health is part of health.

(C) Mental health means that a person will behave positively and think positively.

\section{Question 2:}

What problems do you think students of your age face that might cause mental health problems? Answers:

(G) Teachers in China will force you to finish your homework, but American teachers will not care about that.

(F) CYOS not only need to learn to speak English, but also learn professional terms in other subjects.

\section{Question 6\& 7:}

Now please tell me the factors that hinder/facilitate you to seek help from each source you mentioned.

(A) That counselor gossips about the students.

(B) I think it's easy to put pressure on your friends.

(H) Usually I don't go to my parents, because they would say "Learn to be tolerant".

(E) If I suffered a major blow or mental disorders, I would go to the school counselor.

(F) Every day after lunch we go to adviser's classroom, we can ask any questions at this time.

\section{Codes}

CYOS' understandings of $\mathrm{MH}$

Pressures that CYOS might face

Perceived barriers

Perceived facilitators

Fig. 1. The coding process in data analysis.

Source: own research. 
Table 1

The background of participants

\begin{tabular}{ccccc}
\hline Participants & Gender & Age & School type & Years in US \\
\hline Student A & Male & 15 & Mixed school & 2 \\
Student B & Female & 15 & Mixed school & 1 \\
Student C & Female & 15 & Single-sex school & 2 \\
Student D & Male & 14 & Mixed school & 2 \\
Student E & Female & 15 & Mixed school & 2.5 \\
Student F & Male & 15 & Single-sex school & 2 \\
Student G & Male & 14 & Single-sex school & 2 \\
Student H & Male & 13 & Single-sex school & 2 \\
\hline
\end{tabular}

Source: own research.

\section{Data collection}

In this research, data was collected through online semi-structured interviews since the key to qualitative interviewing is 'grasping the meaning' (Punch \& Oancea, 2014). All the interviews were conducted on-line, because first, the participants were in either China or US and online interviews could save time and money; second, all of these participants have WeChat accounts, personal computers and mobile phones, and they are used to the form of online lessons. They felt at ease when conducting online interviews.

In order to make the interview questions clear and understandable, a pilot study was done with one student (CYOS). Open-ended questions were asked to obtain in-depth understandings of CYOS' perceptions of the topic and generate unexpected answers (Robson \& McCartan, 2016). The length of interviews varied, but was generally between 22 to 31 minutes. All the interviews were audio-recorded for further transcription, translation and data analysis.

\section{Data analysis}

Thematic analysis was used to analyse qualitative data from interviews (Joffe \& Yardley, 2004). The Figure 1 and 2 demonstrate how the researcher coded the data and how sub-themes can be related to the main themes.

\section{Codes}

\section{Themes}

1. CYOS' understandings of $\mathrm{MH}$

2. Pressures that CYOS might face

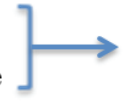

A general overview of how young people perceive $\mathrm{MH}$ and the pressures that they face

CYOS' perceived barriers and facilitators to seek help

Fig. 2. Thematic network in the data analysis Source: own research. 


\section{FINDINGS}

Findings show that all the students have a certain understanding of $\mathrm{MH}$, and these young people consider parents, teachers and friends as main help-seeking sources. School counsellors are the second most frequently mentioned source, followed by doctors being perceived as a source to seek help by half of the students. With the development of the Internet, some students believe that mental health websites have gradually become popular sources. One interviewee referred to the overseas studies Agency; and two referred to relying on themselves.

\section{CYOS' help-seeking preferences}

Four preferences were found in the data. First, CYOS are reluctant to seek professional help, especially school counsellors and mental health doctors. Most students do not think their problems could be serious enough to require a professional intervention. Some students worry about that the counsellor might leak their secrets, and some are concerned about the complicated process and high cost of treatment. Second, the majority of CYOS prefer informal help-seeking sources such as friends and parents to formal sources. Half of the students prefer to seek help from friends and parents to advisers, counsellors and doctors. Three students prefer to seek help from professionals, with one student relying only on professional help. Third, there is no obvious preference for self-reliance. Only two students refer to relying on themselves. Forth, the type of problem is likely to determine what sources to seek help. Seven participants clearly expressed their help-seeking preferences but one participant believed the preference would depend on the type of problem. She would seek help from parents for problem in daily life and from teachers and friends for academic problems.

\section{CYOS' perceived barriers and facilitators to seek help}

In the interviews, the participants were asked whether they would seek help from the sources they mentioned and explain why they would seek help from them or not. In general, five barrier themes and six facilitator themes emerged from the data.

\section{Perceived barriers for CYOS to seek help}

According to the frequency of being mentioned in the study, five barrier themes are as follows.

Perceiving the problems as not serious. This theme mainly refers to seeking help from professionals. In the interviews, six students believed that it was unnecessary to seek help from professionals if the problem is not serious. For example (F) "School counsellor? [Looking a bit surprised.] Basically no one would go to see them. Our school does not take this seriously, because no one has serious problems, such as suicide and self-harm."

Negative attitude toward help seeking. This theme mainly refers to seeking help from informal sources such as parents and friends. Participants' negative 
attitudes mainly attribute to parents' ignorance of their children's situation, the lack of attention to their children's mental health, as well as both parents' and friends' negative feedback and lack of knowledge, which make them worry about the effect of seeking help. For example,

(B) Parents don't understand their children's situation or mental health. They don't care about these... [Raising her tone.] Their knowledge of mental health is far less than ours, so I think it is particularly unreliable to go to parents. They don't understand it and have little knowledge about it.

Students B, G and H also added that they would not ask their parents for help because they may be blamed, which made them disappointed and upset. Student C does not seek help from friends because she believes that her friends might take pleasure from her being in troubles and laugh at her.

Not willing to burden somebody else. Participants are not willing to burden others such as their parents and friends. Students A and G do not want to make their parents worried, and student B does not hope to put pressure on friends.

Lack of understanding of the process of mental health support. Most of participants had little knowledge of the process to acquire professional $\mathrm{MH}$ help. Participant $\mathrm{C}$ talked about her stress to seek help from $\mathrm{MH}$ doctors by stating that she believed the process of seeing a doctor must be complicated, and the doctors would usually make a fuss over a trifle. Students are basically not clear about the price of $\mathrm{MH}$ counseling services, simply analogising it to the price of general medical treatment. For example, student $\mathrm{C}$ complained about the cost of seeing a doctor, and she believed it would also be expensive to see a $\mathrm{MH}$ doctor. Some students confuse professional counselling hot lines with fraud calls.

Confidentiality and trust. Participants A and C worried about the protection of their privacy. (C) "I don't usually seek help from friends. They may give away my secrets. I don't like people to reveal my privacy. I don't tell them, just in case they will."

\section{Perceived facilitators for CYOS to seek help}

In the previous studies, facilitators were relatively less researched. This study tries to explore more perceived facilitators for CYOS to seek help.

Positive attitude towards help seeking. All of the eight participants emphasised that positive attitude could promote help-seeking behaviour. Their positive attitude is determined by the usefulness of suggestions, whether someone listens to and comforts them, whether parents or friends understand their situations well and are able to provide specific feedback, the experience and professionalism of help providers, as well as the good characteristics of help providers.

Positive relationships with help providers. Positive relationship with parents, friends and school staff could promote communication and encourage help-seeking behaviours. For example: 
(A) I have an older brother. Actually he is an older schoolmate. He gives me special care... He hopes that I could take fewer detours in my life. He is super good. If I have any questions, I can ask him for help.

Perceiving the problem as serious. Four of the participants talked about their perceived serious problems including self-harm, suicide, schizophrenia, continuous depression for more than a week, psychological trauma, continuous decline in academic performance, and extreme case such as smoking weed.

Easy access. This theme has two meanings: frequent meeting opportunities and convenient location. Three students meet their friends and teachers frequently, and one has video chat with parents every day, which creates higher chances to seek help.

Confidentiality and trust. Two students showed strong confidence in help providers. Student A listed three most trusted people and would be more likely to seek help from them for mental health difficulties. Student G stated that he trusted the adviser who would provide satisfying help and would not make a bad impression on him.

Previous habit of seeking help. One participant mentioned that he had formed a habit to seek help from teachers when he was in China, so that he would naturally turn to American teachers for help.

\section{DISCUSSION}

\section{Main findings}

There are generally four preferences for CYOS to seek help when they are in difficulties. First, CYOS are reluctant to seek help from professionals, especially school counsellors and doctors. Second, the majority of CYOS prefer informal help-seeking sources such as friends and parents to formal sources, but there is no significant difference in the preferences for friends and parents. Third, self-reliance is not so obviously preferred as previous literature. Forth, the choice of help-seeking source is likely to depend on the type of problems.

What is more, the participants identified with five barriers and six facilitators in this research. The barrier themes include perceiving the problems as not serious, negative attitudes toward help seeking, being not willing to burden somebody else, lack of understanding of the process of mental health support, and confidentiality and trust. The facilitator themes refer to positive attitudes towards help seeking, positive relationships with help providers, perceiving the problem as serious, easy access, confidentiality and trust, and previous habit of seeking help.

\section{Limitations and suggestions for further research}

There are some limitations in regard to the sampling and the research methods. First, this research used eight samples and they were basically recruited from students who were studying in the US. Thus, the samples are homogeneous and could not represent all CYOS and thus lacked generalisability. 
Future researchers interested in this topic can recruit larger samples of overseas students who are studying in different countries since education systems and $\mathrm{MH}$ services may vary from country to country. Secondly, due to the limited time, only interviews were applied for data collection, which has an impact on the credibility and trustworthiness of the research. According to Diane G. Cope (2014), with triangulation, researcher could use multiple methods to gain an articulate and comprehensive view and enhance the quality of data. Future researchers could consider developing a questionnaire together with interviews to collect data.

\section{Pedagogic implications}

Since this research generates deep insights into the pedagogic issues about CYOS' preferences in help seeking, it has significant implications for the future practice of $\mathrm{MH}$ education and services. It can be seen from this research that CYOS generally have relatively limited knowledge of recognising the symptoms of mental health problems, as well as understandings of the process to seek professional help. Their most preferred informal resources also lack the knowledge of how to provide appropriate help. Schools should provide information in courses or handbooks about the symptoms of $\mathrm{MH}$ problems, introduction to the process of getting access to professional sources, and how peers and parents provide appropriate help. It is also very important to cultivate good help-seeking habits and make good MH preparations before CYOS go abroad.

From parents' perspective, they should pay more attention to their children's MH, learn knowledge of recognition of the symptoms of $\mathrm{MH}$ problems, and learn how to provide appropriate support when needed. Government MH sectors, schools and overseas studies agencies could help design courses or handbooks on help seeking based on their expertise and accumulated experience in this field. From the perspective of students, they should learn more knowledge about $\mathrm{MH}$ and actively communicate with parents, friends, advisers and any other sources available to seek help if they are in difficulties. To conclude, $\mathrm{MH}$ of CYOS is an issue for the entire community. Not only agencies, governments and organisations, but all people, both professional and non-professional, ought to shoulder the responsibility to help them maintain good $\mathrm{MH}$.

\section{REFERENCES}

[1] Blignault, I., Ponzio, V., Rong, Y., \& Eisenbruch, M. (2008). A qualitative study of barriers to mental health services utilisation among migrants from mainland China in South-East Sydney. International Journal of Social Psychiatry, 54(2), 180-190.

[2] Boldero, J., \& Fallon, B. (1995). Adolescent help-seeking: What do they get help for and from whom? Journal of Adolescence, 18(2), 193-209.

[3] Bryman, A. (2015). Social research methods (5th ed.). Oxford: Oxford University Press.

[4] Cakar, F. S., \& Savi, S. (2014). An exploratory study of adolescent's help-seeking sources. Procedia - Social and Behavioural Sciences, 159, 610-614.

[5] Commonwealth Department of Health and Aged Care. (2000). National action plan for pro- 
motion, prevention and early intervention for mental health 2000. Mental Health and Special Programs Branch, Commonwealth Department of Health and Aged Care, Canberra.

[6] Cope, D. (2014). Methods and meanings: Credibility and trustworthiness of qualitative research. Oncology Nursing Forum, 41(1), 89-91.

[7] Dubow, E. F., Lovko Jr, K. R., \& Kausch, D. F. (1990). Demographic differences in adolescents' health concerns and perceptions of helping agents. Journal of Clinical Child Psychology, 19(1), 44-54.

[8] Eisenhardt, K. M. (1989). Building theories from case study research. Academy of Management Review, 14(4), 532-550.

[9] Gray, D. (2018). Doing research in the real world (4th ed.). Los Angeles: SAGE Publications Ltd.

[10] Green, H., McGinnity, Á., Meltzer, H., Ford, T. J., \& Goodman, R. (2005). Mental health of children and young people in Great Britain, 2004. Basingstoke: Palgrave Macmillan.

[11] Gulliver, A., Griffiths, K. M., \& Christensen, H. (2010). Perceived barriers and facilitators to mental health help-seeking in young people: A systematic review. BMC Psychiatry, 10(1), 1-9.

[12] Ho, K. P., Hunt, C., \& Li, S. (2008). Patterns of help-seeking behaviour for anxiety disorders among the Chinese speaking Australian community. Social Psychiatry and Psychiatric Epidemiology, 43(11), 872-877.

[13] Joffe, H., \& Yardley, L. (2004). Content and thematic analysis. In: D. F. Marks \& L. Yardley (Eds.), Research methods for clinical and health psychology (pp. 56-68). London: SAGE Publications Ltd.

[14] Kessler, R. C., Chiu, W. T., Demler, O., Merikangas, K. R., \& Walters, E. E. (2005). Prevalence, severity, and comorbidity of 12-month DSM-IV disorders in the National Comorbidity Survey Replication. Archives of General Psychiatry, 62(6), 617-627.

[15] Lawrence, D., Johnson, S., Hafekost, J., Boterhoven de Haan, K., Sawyer, M., Ainley, J., \& Zubrick, S. R. (2015). The mental health of children and adolescents: Report on the Second Australian Child and Adolescent Survey of Mental Health and Wellbeing. Australian Government. Department of Health.

[16] Leavey, G., Rothi, D., \& Paul, R. (2011). Trust, autonomy and relationships: the help-seeking preferences of young people in secondary level schools in London (UK). Journal of Adolescence, 34(4), 685-693.

[17] Lubman, D. I., Cheetham, A., Jorm, A. F., Berridge, B. J., Wilson, C., Blee, F., Mckay-Brown, L., Allen, \& N., Proimos, J. (2017). Australian adolescents' beliefs and help-seeking intentions towards peers experiencing symptoms of depression and alcohol misuse. BMC Public Health, 17(1), 1-12.

[18] Merikangas, K. R., He, J. P., Burstein, M., Swendsen, J., Avenevoli, S., Case, B., Georgiades, K., Heaton, L., Swanson, S., \& Olfson, M. (2011). Service utilisation for lifetime mental disorders in US adolescents: results of the National Comorbidity Survey-Adolescent Supplement (NCS-A). Journal of the American Academy of Child E Adolescent Psychiatry, 50(1), 32-45.

[19] Offer, D., Howard, K. I., Schonert, K. A., \& Ostrov, E. (1991). To whom do adolescents turn for help? Differences between disturbed and nondisturbed adolescents. Journal of the American Academy of Child E Adolescent Psychiatry, 30(4), 623-630.

[20] Punch, K., \& Oancea, A. (2014). Introduction to research methods in education. London: SAGE Publications Ltd.

[21] Rickwood, D. J. (1992). Help seeking of psychological problems in late adolescence [Unpublished doctoral thesis]. Australian National University.

[22] Rickwood, D. J., Deane, F. P., \& Wilson, C. J. (2007). When and how do young people seek professional help for mental health problems? Medical Journal of Australia, 187(Suppl. 7), 35-39.

[23] Rickwood, D., Deane, F. P., Wilson, C. J., \& Ciarrochi, J. (2005). Young people's help-seeking for mental health problems. Australian E-journal for the Advancement of Mental Health, 4(3), 218-251.

[24] Rickwood, D. J., Mazzer, K. R., \& Telford, N. R. (2015). Social influences on seeking help from mental health services, in-person and online, during adolescence and young adulthood. BMC Psychiatry, 15(1), 1-9.

[25] Robson, C., \& McCartan, K. (2016). Real world research: a resource for users of social research methods in applied settings. Wiley. 
[26] Rowe, S. L., French, R. S., Henderson, C., Ougrin, D., Slade, M., \& Moran, P. (2014). Help-seeking behaviour and adolescent self-harm: A systematic review. Australian \& New Zealand Journal of Psychiatry, 48(12), 1083-1095.

[27] Sheffield, J. K., Fiorenza, E., \& Sofronoff, K. (2004). Adolescents' willingness to seek psychological help: Promoting and preventing factors. Journal of Youth and Adolescence, 33(6), 495-507.

[28] Tung, W. C. (2011). Acculturative stress and help-seeking behaviours among international students. Home Health Care Management \& Practice, 23(5), 383-385.

[29] West, J. S., Kayser, L., Overton, P., \& Saltmarsh, R. (1991). Student perceptions that inhibit the initiation of counseling. The School Counselor, 39(2), 77-83.

[30] Wintre, M. G., \& Crowley, J. M. (1993). The adolescent self-concept: A functional determinant of consultant preference. Journal of Youth and Adolescence, 22(4), 369-383.

[31] World Health Organisation. (2001). Basic documents (43rd ed.). Geneva: World Health Organisation.

[32] World Health Organisation. (2002). Prevention and promotion in mental health. Mental health: evidence and research. Geneva: Department of Mental Health and Substance Dependence.

[33] Zachrisson, H. D., Rödje, K., \& Mykletun, A. (2006). Utilisation of health services in relation to mental health problems in adolescents: a population based survey. BMC Public Health, 6(1), 34. 
